\title{
Salinity-triggered compositional and metabolic responses of autotrophic prokaryotes in Tibetan lacustrine sediments
}

Jun Liu

Sun Yat-Sen University

\section{Yun Fang}

China University of Geosciences

Jian Yang

China University of Geosciences

Hongchen Jiang ( $\nabla$ hongchen.jiang@gmail.com )

https://orcid.org/0000-0003-1271-7028

\section{Brian P. Hedlund}

University of Nevada Las Vegas

\section{Zhengshuang Hua}

Dartmouth College

\section{Yizhi Sheng}

Miami University

\section{Geng Wu}

China University of Geosciences

Jieliang Liang

South China Normal University

\section{Baogang Zhang}

China University of Geosciences

\section{Linan Huang}

Sun Yat-Sen University

\section{Wenjun Li}

Sun Yat-sen University

\section{Jintian Li}

South China Normal University

\section{Wensheng Shu}

South China Normal University

\section{Hailiang Dong}

\section{Miami University}

\section{Brett J. Baker}




\section{Research}

Keywords: Carbon fixation, Salinity gradient, Lacustrine sediments, Autotrophic microbial community, Genome-resolved metagenomics, Biogeochemical cycles

Posted Date: January 22nd, 2020

DOI: https://doi.org/10.21203/rs.2.21623/v1

License: (c) (i) This work is licensed under a Creative Commons Attribution 4.0 International License. Read Full License 


\section{Abstract}

\section{Background}

Autotrophic prokaryotes are crucial participants in the global carbon cycle, and autotrophic carbon fixation contributes approximately $50 \%$ of the global net primary production in aquatic ecosystems per year. Salinity is a prominent regulator structuring microbial communities in diverse aquatic ecosystems. However, little information is available regarding the compositional and physiological response of autotrophic microbial communities to salinity change. Here, we used genome-resolved metagenomics to study autotrophic microbial communities in 25 Tibetan lacustrine sediments with a salinity gradient (from $0.54 \%$ o to $82.6 \%$ o).

Results

117 metagenome-assembled genomes (MAGs) with carbon fixation potential belonging to 12 phyla were retrieved, of which approximately $21 \%$ were not affiliated with the known orders, suggesting taxonomically diverse autotrophic assemblages in sediments. The total abundance of these putative autotrophs decreased significantly with increasing salinity, and the variation of sediment autotrophic communities was mainly driven by salinity, $\mathrm{pH}$ and TOC. Notably, a change in the predominant lineage from Betaproteobacteria to Deltaproteobacteria was observed along the salinity gradient, and the dominant pathway for carbon fixation shifted from the Calvin-Benson-Bassham (CBB) cycle to more energy efficient Wood-Lungdahl (WL) pathway with glycolysis from Entner-Doudoroff to more exergonic Embden-Meyerhof-Parnas, demonstrating that the physiological efficiency increases from freshwater to hypersaline autotrophic communities. Metabolic inference revealed major links for carbon fixation to the oxidation of reduced sulfur compounds, ferrous iron and carbon monoxide, denitrification and nitrogen fixation in these MAGs, as well as the occurrence of dissimilatory sulfate reduction and the WL pathway dominating hypersaline sediments, greatly extending the understanding of metabolic versatility and diverse ecological niches of autotrophic microorganisms.

\section{Conclusions}

This study provided a systematic attempt to characterize the response of carbon fixation pathways to salinity and the knowledge essential for revealing ecological roles of autotrophic prokaryotes in aquatic habitats. These findings suggest with increased salinity, physiological efficiency of the autotrophic community increases, which has important implications for understanding the carbon budget in aquatic ecosystems.

\section{Background}

Autotrophic carbon fixation is considered to underlie nearly all biological processes on Earth [1], and provides approximately $50 \%\left(\sim 50 \mathrm{Pg} \mathrm{C} \mathrm{yr}^{-1}\right)$ of the annual global net primary production in aquatic ecosystems [2-4], thus it is of great importance to understand the carbon fixation mechanisms and 
physiologies of these autotrophs in aquatic habitats. To date, eight pathways have been confirmed to fix inorganic carbon by autotrophic organisms, including the Calvin-Benson-Bassham (CBB) cycle, reductive citric acid (rTCA) cycle, Wood-Ljungdahl (WL) pathway, 3-hydroxypropionate (3-HP) bicycle, 3hydroxypropionate/4-hydroxybutyrate (HP/HB) cycle, dicarboxylate/hydroxybutyrate (DC/HB) cycle, reductive glycine ( $\mathrm{rGly}$ ) pathway and reversed oxidative tricarboxylic acid (roTCA) cycle [5-9]. In previous community-level studies, markers for carbon fixation (such as rbcL and aclB) were leveraged to explore the composition and diversity of autotrophs $[4,10]$. However, recent studies have shown that forms IV and IV-like RubisCOs encoded by rbcLS genes may perform functions in methionine salvage, sulfur metabolism and D-apiose catabolism, rather than carbon fixation [11, 12]. Therefore, the characterization of carbon fixation based on single genes can be inaccurate. Moreover, autotrophs can perform other important ecological functions such as nitrogen fixation, iron and sulfur oxidation, and hydrogen utilization $[13,14]$. Recent studies had demonstrated that as important autotrophic species, chemoautotrophs can use inorganic molecules such as $\mathrm{CO}, \mathrm{H}_{2} \mathrm{~S}$, and ferrous iron as electron donors to convert $\mathrm{CO}_{2}$ to organic compounds, and significantly contribute to carbon sequestration via the abovementioned metabolisms $[15,16]$. Therefore, reconstructing individual genomes from nature through genome-resolved metagenomics is more informative to understand carbon fixation and the coupling of carbon and other elements (e.g., N, S and Fe) at a community level.

Saline lakes compose $\sim 50 \%$ of total inland aquatic ecosystems [17]. In saline lakes, microorganisms are major drivers of carbon fluxes $[18,19]$, which are considered to contribute significantly to global carbon cycle $[20,21]$. Numerous studies have shown salinity as an important regulator of community structure and microbial functional groups in diverse lake ecosystems [4, 22-24], likely due to energetic constraints [25]. It is likely to be explained that bioenergetic constraints determine the upper salt concentration limit at which different dissimilatory processes occur in nature, and the amount of energy generated during dissimilatory metabolisms and the mode of osmotic adaptation used will determine whether a certain type of microorganism can survive in a salinity zone [25]. However, there is a fundamental knowledge gap of how autotrophic community structure and especially physiology respond to salinity change in saline lakes.

The Tibetan Plateau is the largest and highest plateau on Earth and contains thousands of pristine lakes with stratified biogeochemical gradients such as salinity, $\mathrm{pH}$ and nutrients [26, 27], which provide an ideal study ground to fill the knowledge gap. Here we collected 25 sediment samples along a salinity gradient $(0.54 \%$ o to $82.6 \%$ o) in Xiaochaidan Lake and an inflow Tataling River (Fig. 1a). Genome-resolved metagenomic analysis and metabolic inference revealed the taxonomy and biogeochemical capabilities of 117 potential carbon-fixing microbes in this ecosystem. The sites were delineated into five groups based on salinity, which were compared to examine shifts in community structure and metabolic potential in response to the gradient.

\section{Results And Discussion}




\section{Autotrophic community structure in sediments and environmental determinants}

A total of $1,926 \mathrm{~Gb}$ of metagenomic raw data were obtained for 25 sediment samples, and approximately $10 \mathrm{~Gb}$ of scaffolds ( $\geq 2000 \mathrm{bp}$ ) were generated (Additional file 2: Table S1). After binning of these assembled fragments, we identified 117 metagenome-assembled genomes (MAGs) with the capacity of carbon fixation (Additional file 3: Table S2). According to the 95\% ANI-based species demarcation [28], these MAGs represented 117 species, and genomic characteristics were summarized in Additional file 3 : Table S3. Their genome sizes ranged widely from $\sim 1.1$ to $7.1 \mathrm{Mb}$ with estimated completeness of $43 \%-100 \%$ and $<3.5 \%$ single-gene redundancies, among which approximately $19 \%$ and $79 \%$ were classified as high-quality and medium-quality drafts, respectively, according to the genomic standards [29]. The result is likely attributed to the high community diversity in Tibetan sediments [26]. These MAGs varied greatly from $30-74 \%$ in the GC content, of which 44\% had high GC content ( $\geq 60 \%$ ).

Phylogenomic analysis showed that the 117 MAGs were affiliated with eleven bacterial phyla and one archaeal phylum, including the Proteobacteria $(n=85)$, Cyanobacteria $(n=7)$, Firmicutes $(n=5)$, Bacteroidetes $(n=4)$, Deinococcus-Thermus $(n=4)$, Gemmatimonadetes $(n=4)$, Acidobacteria $(n=2)$, Verrucomicrobia $(n=1)$, Chloroflexi $(n=1)$, Elusimicrobia $(n=1)$, Nitrospirae $(n=1)$, and Euryarchaeota $(n$ $=2$ ) (Fig. 1b and Additional file 1: Figure S1), in agreement with the taxonomical information found in Tibetan sediments [26]. Note that approximately $21 \%$ of these MAGs $(n=24)$ are not affiliated with known orders, greatly expanding our knowledge of the autotrophic diversity and physiologies in nature. The findings suggested that the autotrophic community in the studied sediments was taxonomically diverse in phylogeny. Relative abundances of each MAG were estimated for each sample (Fig. 2 and Additional file 5: Table S4), and results revealed their total relative abundance across sample between $1.96 \%$ and $11.4 \%$.

Canonical correspondence analysis indicated that $\mathrm{pH}$, salinity, TOC and their interactions explained approximately $15.4 \%, 12.9 \%, 10.9 \%$ and $5.1 \%$ of the observed variation in the autotrophic community, respectively (Fig. 1C). The finding is consistent with numerous studies that salinity and $\mathrm{pH}$ are two most important determinants of microbial diversity and community structure in Tibetan sediments $[4,26,27$, 30]. In addition to salinity and $\mathrm{pH}, \mathrm{TOC}$ also frequently shapes microbial community structure in aquatic ecosystems [31,32]. Microorganisms surviving under high salinity require more energy for a variety of processes, especially osmotic balance [25]. TOC could facilitate the growth of heterotrophs and facultative autotrophs under high salinity, which is particularly stressful for autotrophic energy generating pathways $[33,34]$. A recent study demonstrated that nutrients (TOC and TN) availability contributed to the response of autotrophic microbial community to salinity and mitigated the salinity constraints [4]. Thus, TOC is also an important environmental driver of the autotrophic community structure. In short, the findings indicated that these physicochemical conditions exerted a critical impact on autotrophic microbial community. 
Remarkably, canonical correspondence analysis distinguished these sediments into five categories, and this clustering pattern matched the salinity gradient (Fig. 1c, Fig. 1d and Fig. 1e), which was confirmed by the significant correlation $\left(R^{2}=0.953, P<0.001\right)$ between the total relative abundance of these MAGs and salinity (Fig. 1d). The results also illustrated that salinity played a more important role in structuring the autotrophic community than $\mathrm{pH}$ and TOC, in agreement with previous findings in aquatic ecosystems [4]. Therefore, these sediment samples were divided into five salinity groups: G1 (S01-S06, salinity 0.6\%o), G2 (S07-S10, 1.8-5.9\%o), G3 (S11-S15, 12.0-43.9\%o), G4 (S16-S20, 49.7-70.7\%o), and G5 (S21-S25, $75.5-82.6 \%$ ).

\section{Changes in the sediment autotrophic community and carbon fixation pathways along a salinity gradient}

Across the five salinity groups, an abundance-salinity correlation was observed that the average autotrophic abundance decreased from G1 to G5 (one-way ANOVA, $P<0.001$, Fig. 1e). This inverse correlation is likely due to two reasons: 1) salinity-derived osmotic stress directly limits metabolic activity of carbon fixers, and consumes their energy to maintain cellular osmotic balance, resulting in a decrease in autotrophic biomass; and 2) high salinity decreases the solubility and diffusion coefficient of $\mathrm{CO}_{2}$, thus limiting its availability for carbon fixation, and finally autotrophic biomass decreases [25, 35]. On the other hand, the autotrophic community composition was significantly different among salinity groups (Anosim, Adonis and MRPP, all P = 0.001). The community in the freshwater group $\mathrm{G} 1$ (with the lowest salinity) was mainly composed of the Betaproteobacteria (average relative abundance, $7.28 \%$ ) and Deltaproteobacteria (1.23\%), while the Deinococcus-Thermus (2.50\%) and Deltaproteobacteria (0.95\%) were predominant in the second lowest salinity G2 (Additional file 1: Figure S2). In G3-G5 (from moderate to high salinity), the Deltaproteobacteria $(0.86-1.57 \%)$ dominated, followed by the Gammaproteobacteria and Cyanobacteria. More specifically, at the species level, no MAGs were shared between G1 and G5 (Additional file 1: Figure S3), in agreement with previous findings that the freshwater taxa could rarely survive under hypersaline conditions [36, 37], implying that the dominant pathway of carbon fixation may be different between the freshwater and hypersaline conditions. Analyses of the top 3 dominant species per salinity group revealed that a specific dominant species from the corresponding group had a higher relative abundance than that in the other groups (one-way ANOVA, all $P<0.01$ ), except the Desulfobacteraceae S20.Bin068, demonstrating that these dominant species have adapted to specific salinity levels (Fig. 2). Previous studies have provided evidences that most known bacteria can growth well under $\mathrm{pH} 7.5-8.8$ instead of a wide range of salinity (freshwater to hypersaline) [26]. Thus, it is reasonable to conclude that salinity has a greater impact than $\mathrm{pH}$ on autotrophic microbial community structure in Tibetan sediments.

Among these currently known carbon fixation pathways [5-7], five were identified in the 117 MAGs, of which $35.0 \%, 32.5 \%, 17.1 \%, 12.0 \%$ and $3.4 \%$ harbored the CBB cycle, WL pathway, rGly pathway, rTCA cycle and 3-HP bicycle, respectively (Fig. 2). Ribulose-1,5-bisphophate carboxylase/oxygenase (RubisCO), 
which is considered to be the most abundant enzyme on Earth, is integral to carbon fixation via the CBB cycle $[11,12]$. However, recent studies reported that forms IV and IV-like RubisCOs might perform other functions instead of carbon fixation [11, 12]. Hence, we constructed a phylogenetic tree of the RubisCO large subunit to determine the RubisCO forms present in the MAGs generated here (Fig. 3a and Additional file 1: Figure S4). This revealed that among 41 MAGs containing the CBB cycle, almost all had the potential to encode forms I or/and II RubisCOs, except Methanothrix sp. S02.Bin032 that possessed forms II/III and III-a RubisCOs-encoding rbcL genes. Forms III and II/III RubisCOs, primarily found in archaea, enable light-independent $\mathrm{CO}_{2}$ incorporation into sugars derived from nucleotides like adenosine monophosphate (AMP) $[11,38]$. The findings illustrated that all above 41 MAGs carried the potential to fix atmospheric carbon dioxide via the CBB cycle.

Exploring relationships between taxa and carbon fixation pathways showed that all MAGs affiliated with the Deinococci $(n=4)$ and Epsilonproteobacteria $(n=5)$ harbored the rTCA cycle, while MAGs belonging to the Cyanobacteria $(n=7)$ and Gemmatimonadetes $(n=4)$ exclusively coded for CBB cycle and 3-HP bicycle, respectively (Fig. 2 and Fig. 3c). Meanwhile, 91\% of the MAGs belonging to the Betaproteobacteria $(n=22)$ and Gammaproteobacteria $(n=11)$ contained the CBB cycle with the WL pathway identified in $\sim 88 \%$ of the 27 deltaproteobacterial MAGs (Fig. 2). There was a significant negative correlation $(P<0.001)$ between the number of the CBB cycle-containing MAGs and salinity (Fig. 4), supporting the view that the diversity of the CBB-performing autotrophic prokaryotes decreases with enhancing salinity in aquatic ecosystems [4]. For the main carriers of the CBB cycle, taxonomy shifted from the Betaproteobacteria in G1 to the Cyanobacteria and Gammaproteobacteria in G2 and G3, to the Cyanobacteria in G4, and finally to the Gammaproteobacteria in G5, which is consistent with the conclusion of a recent study that the Betaproteobacteria dominated the CBB-performing autotrophic community in the freshwater lake and the Gammaproteobacteria dominated the hypersaline lake [4]. Moreover, for the rTCA pathway, the dominant carriers belonged to the Epsilonproteobacteria in $\mathrm{G} 1$ (the average relative abundance: $\sim 0.47 \%)$ and the Deinococci in G2-G5 (0.18-2.50\%), respectively. The WL pathway were mainly encoded by the Deltaproteobacteria in all five salinity groups.

Comparison of carbon fixation pathways among the five salinity groups revealed that the CBB cycle was predominant in the freshwater $\mathrm{G} 1$ samples, with the rTCA cycle dominating in the second lowest salinity G2 ( $t$ test, all $P<0.001$ ). Comparative analysis showed that the CBB cycle-containing MAGs in $G 1$ had a higher abundance in comparison with that in the other groups (one-way ANOVA, $P<0.01$ ). The top 3 dominant MAGs (Rhodoferax sp. S03.Bin061 and Hydrogenophaga sp. S05.Bin024 and S04.Bin021) in G1 encoded the CBB cycle and the top 2 dominant MAGs (Trueperaceae sp. S10.Bin132 and S23.Bin013) in $\mathrm{G} 2$ encoded rTCA cycle. The discovery of the potential autotrophic Rhodoferax bacterium was inconsistent with previous results that members of the Rhodoferax could not fix $\mathrm{CO}_{2}[39,40]$, expanding the autotrophic diversity and the niche of the Rhodoferax. Besides, previous studies also gave evidences that members of the genus Hydrogenophaga (e.g., Hydrogenophaga pseudoflava) could use the CBB cycle for carbon fixation [41]. In saline to hypersaline sediments (G3-G5), autotrophs mainly contained the CBB and WL pathways, and the WL pathway became the most important in the G5 samples (Fig. 3b). 
Statistical analysis indicated a significantly positive $(P<0.001)$ correlation between the fraction of MAGs with the WL pathway and salinity (Fig. 4). There may be two explanations for this: 1) autotrophs need to reallocate energy to accumulate inorganic and organic osmoregulators (e.g., $\mathrm{K}^{+}$, sugars, polyols and quaternary amines) to deal with intracellular osmotic stress caused by salinity [42, 43]. In this instance perhaps the more energy-efficient (no ATP consumption) WL pathway provides an advantage for survival in comparison to the energy-demanding (9 ATP consuming) CBB cycle [44]. A recent study indicated that the $\mathrm{CO}_{2}$-reduction via WL is more ATP-efficient and yields more biomass than $\mathrm{CO}_{2}$-carboxylation dependent pathways (including CCB, rTCA and 3-HP) [7]. 2) Primordial life on earth may have started in hypersaline environments [45], and the WL pathway is considered to be the most ancient pathway for carbon fixation $[46,47]$, so microbes containing the WL pathway may be more suitable for living in high salinity environments. The inference of an operative WL pathway in the G5 dominant Desulfotignum sp. S23.Bin123 and S15.Bin083 was supported by previous research [48-50]. Overall, these pathway shifts along the salinity gradient suggest that it provides a selective advantage between different mechanisms for carbon fixation.

\section{Metabolic potential of sediment autotrophs in response to salinity}

We examined the potential of these microbes for driving biogeochemical cycles. To do this, the important pathways and related key genes in carbon, nitrogen, sulfur and iron metabolisms and respiration were searched (Fig. 2 and Additional files: Tables S7-S10). This revealed that these MAGs possessed the potential to perform central carbohydrate metabolism such as glycolysis/gluconeogenesis, TCA cycle, and pentose phosphate pathway (PPP). Approximately $56 \%$ of these MAGs contained glycolysis pathways including Embden-Meyerhof-Parnas (EMP, $n=51)$ and Entner-Doudoroff $(E D, n=19)$, of which five (Hydrogenophaga S05.Bin024 and S07.Bin178, Maritimibacter S23.Bin089, Sulfurovum S06.Bin221, and Rhodobacteraceae S06.Bin070) contained both pathways. It is not unprecedented to have both catabolic pathways in the same organism, such as Polaromonas sp. JS666 and Hydrogenophaga b174 $[51,52]$. Interestingly, previous reports revealed that this kind of bacteria usually possessed an incomplete PPP [51, 52], but Hydrogenophaga S07.Bin 178 contained a complete PPP. These findings greatly increase our knowledge of catabolism mechanisms of these genera. Further analysis showed a significant positive trend $(P<0.001)$ between the fraction of MAGs containing the EMP pathway and salinity (Fig. 4). In the highest salinity G5 sites, the top 3 dominants all carried the EMP pathway. This correlation is likely due to that the fermentative EMP pathway yields more energy from $\mathrm{C} 6$ and $\mathrm{C} 5$ sugars than the ED pathway [53], and the additional energy generated is beneficial for autotrophs to resist environmental stresses, especially salinity stress. Furthermore, roughly $41 \%$ of the 117 MAGs might produce energy via the TCA cycle, along with the gluconeogenesis pathway identified in 50\%. Notably, the fraction of MAGs with gluconeogenesis potential showed a significant linear positive relationship $(P<0.001)$ with TOC, whereas it was significantly negatively correlated with salinity $(P<0.001)$. It could be explained that TOC and increased salinity inhibited carbon fixation, resulting in a decline in related glucose yield $[4,33,34$, 54], while facultative autotrophs could utilize organic matter to produce glycose $[4,33,34]$ and possibly 
use gluconeogenesis to maintain energy homeostasis (ATP synthesis) and glucose production. Meanwhile, autotrophs with the EMP pathway would be selected and enriched under high salinity conditions as they had a competitive advantage in glucose utilization over autotrophs with the ED pathway [53]. In addition, although more than a half ( 58\%) of MAGs harbored the oxidative or/and nonoxidative branches of PPP, a major source of NADPH and metabolic intermediates for biosynthetic processes [55], only 14\% had the ability to perform the complete PPP.

Then we identified the coxLMS genes encoding aerobic CO dehydrogenase in 11 MAGs (such as the dominant Hydrogenophaga S05.Bin024, Desulfotignum S14.Bin031, S15.Bin083 and S23.Bin123, and Maritimibacter S23.Bin089), suggesting they are capable of CO oxidization. Previous studies also confirmed that members of the Hydrogenophaga and Desulfotignum genera could oxidize $\mathrm{CO}$ and generate equivalents for nitrate reduction $[49,52]$. The 11 species may be oxidizing $C 0$ formed from photochemical degradation of dissolved organic carbon in aquatic environments and then use the generated electrons to support ATP generation and $\mathrm{CO}_{2}$ fixation $[56,57]$. This $\mathrm{CO}$ oxidation potential showed the highest number in the freshwater $\mathrm{G} 1$ ( $\mathrm{t}$ test, all $\mathrm{P}<0.05$ ), and the highest fraction in the highest salinity $G 5$ sites ( $t$ test, all $P<0.01$ ). Besides, all seven cyanobacterial MAGs code for oxygenic photosynthesis (psa or psb), evidenced by previous findings [58]. The pufABLM genes were detected in several MAGs affiliated with Alphaproteobacteria $(n=3)$, Betaproteobacteria $(n=3)$ and Gemmatimonadetes $(n=3)$, indicating they are potential aerobic anoxygenic photosynthetic (AAP) bacteria [59]. The three betaproteobacterial MAGs (S04.Bin010, Burkholderiales S01.Bin058, and Hydrogenophaga S07.Bin178) with the potential to perform the CBB cycle and aerobic anoxygenic photosynthesis suggests that RuBisCO in AAP bacteria was involved in both $\mathrm{CO}_{2}$ fixation and the central redox cofactor recycling, because $\mathrm{CO}_{2}$ fixation could be used to maintain redox balance by recycling reduced redox cofactors for photoheterotrophic metabolism [60, 61].

In assessing the potential for respiration, genes encoding the $\mathrm{aa}_{3}$ - and $\mathrm{cbb}_{3}$-type cytochrome $\mathrm{c}$ oxidases (coxABCD and ccoNOQP, respectively) and cytochrome bd ubiquinol oxidase (cydAB) were found in these MAGs ( $n=14,33$ and 59, respectively) (Additional file 6: Table S5), indicating that most ( 68\%) putative autotrophs likely utilize oxygen as a terminal electron acceptor in the studied sediments. Note that in comparison with the low-oxygen-affinity $a_{3}$-type oxidase induced under oxic conditions, the $\mathrm{cbb}_{3}$-type and bd oxidases are high-affinity terminal oxygen reductases capable of functioning under microoxic to anoxic conditions [62], and the bd oxidase has a lower energetic efficiency than the heme-copper oxidases ( $\mathrm{aa}_{3}$-and $\mathrm{cbb}_{3}$-type) as it does not pump protons [63]. Given the presence of the ccoNOQP or/and cydAB genes, more than a half $(\sim 56 \%)$ of these potential autotrophs were adapted to microoxic to anoxic conditions. Meanwhile, given the occurrence of genes (coXABCD and ccoNOQP, COXABCD and cydAB, or coxABCD, ccoNOQP and cydAB) encoding the low- and high-affinity oxidases, $\sim 11 \%$ of the MAGs affiliated with the Betaproteobacteria $(n=6)$, Gammaproteobacteria $(n=5)$, Alphaproteobacteria $(n$ $=1$ ) and Epsilonproteobacteria $(n=1)$ could survive under fully aerobic to anoxic conditions, according to previous reports [63-65]. Further statistics revealed the highest species number and fraction of putative 
autotrophic MAGs with the ccoNOQP genes in the freshwater G1 (Fig. 4), while no significant difference was observed in the MAGs with the cydAB genes among the five salinity groups.

\section{Autotrophic sulfur cycling in sediments of different salinities}

Recent studies have revealed the important roles of autotrophs in the biogeochemical sulfur cycle [14, 66]. We found 49 MAGs with dissimilatory sulfite reductase genes (dsrAB) (Additional file 7: Table S6). Phylogeny of concatenated DsrAB proteins indicates 31 reductive and 18 oxidative bacterial-types (Fig. 5a and Additional file 1: Figure S5). Deltaproteobacteria S05.Bin005 likely gained the dsrAB genes by lateral gene transfer (LGT), supporting the fact that this genes in organisms from Deltaproteobacteria may be acquired in multiple LGT events $[66,67]$, as shown in Fig. 5 a. Besides, we summarized seven types of dsr operons in 48 of the 49 MAGs (Fig. 5 b). A recent study reported that the gene composition (dsrAB and dsrD/dsrEFH) of the dsr operon may determine the direction of the dissimilatory pathway between sulfite and sulfide $[66,67]$. Therefore, 23 deltaproteobacterial MAGs were inferred to reduce sulfate to sulfide via the dissimilatory sulfate reduction (dsr) pathway and 13 MAGs affiliated with the Gammaproteobacteria $(n=7)$, Betaproteobacteria $(n=5)$ and Deltaproteobacteria $(n=1)$ likely oxidize sulfide to sulfate through the reverse dsr (rdsr) pathway. Only Desulfotignum S25.Bin111 had the potential to perform both functions, likely depending on oxygen concentration and/or oxidation reduction potential, that increased the number of this especial genomes to 14 (the Deltaproteobacteria $n=5, C a$. Lambdaproteobacteria $n=4$, Actinobacteria $n=4$, and Nitrospirae $n=1)[66,67]$. Desulfotignum species were previously inferred to be sulfate-reducing bacteria [50], but our findings suggested that some specific Desulfotignum species could be both sulfate reducers and sulfide oxidizers, increasing our understanding of ecological roles of these bacteria. In the freshwater G1 samples, MAGs with dsr genes were the least prominent, while rdsr (sulfide oxidation) were the highest ( $t$ test, all $P<0.05$ ), in good agreement with the lowest concentration of sulfate and that the most dominant species Rhodoferax S03.Bin061 and Hydrogenophaga S05.Bin024 and S04.Bin021 had the capability to oxidize sulfide via the rdsr pathway. Besides, although the Rhodoferax and Hydrogenophaga species were evidenced to oxidize reduced sulfur compounds in many studies [52,68], our findings provide a new oxidation mechanism in these genera and strengthen their importance in the sulfur cycle.

The complete SOX (sulfur oxidation) system was detected in 16 MAGs (Additional file 7: Table S6), mainly in the $\mathrm{G} 1$ sites (t test, all $\mathrm{P}<0.001$ ), suggesting they are able to oxidize $\mathrm{S}_{2} \mathrm{O}_{3}{ }^{2-}$ to $\mathrm{SO}_{4}{ }^{2-}$. Meanwhile, we observed partial SOX system (lacking soxCD genes) in another 11 MAGs, meaning the transformation from $\mathrm{S}_{2} \mathrm{O}_{3}{ }^{2-}$ to $\mathrm{S}(0)$ only without going all the way to $\mathrm{SO}_{4}{ }^{2-}$ [69]. Among the abovementioned 11 MAGs, four gammaproteobacterial MAGs including Thioalkalivibrio paradoxus S10.Bin039, Thioalkalivibrio nitratireducens S13.Bin160, Thioalkalivibrio S25.Bin012 and Thiotrichales S21.Bin127 contain the versatility of mechanisms of sulfur cycling. They are able to convert $S(0)$ to $S^{2-}$ via oxygenase/reductases (Sor) and sulfhydrogenases (HydGBAD), and also may oxidize $\mathrm{S}(0)$ to $\mathrm{SO}_{3}{ }^{2-}$ due to the identified sdo (encoding sulfur dioxygenase) and sor genes, depending on environmental 
conditions. Inconsistent with previous conclusions that the Thioalkalivibrio species are sulfur-oxidizing bacteria [70,71], our findings inferred that these organisms might be sulfur reducers as well, suggesting their great adaptability to environmental change. Furthermore, eight MAGs belonging to the Deltaproteobacteria $(n=3)$, Deinococcus-Thermus $(n=3)$, Gammaproteobacteria $(n=1)$ and Acidobacteria $(n=1)$ might also perform $S(0)$ reduction via Sor, HydGBAD and/or sulfur reductase (sreAB). Interestingly, more than a half $(\sim 52 \%)$ of the 117 MAGs contained sqr or/and fccAB genes (encoding sulfide:quinone oxidoreductase and sulfide dehydrogenase, respectively) and thus might be able to directly oxidize sulfide to sulfur. Additionally, around 38\% of the MAGs, mainly in G1 sites (t test, all $\mathrm{P}<0.05$ ), likely utilize $\mathrm{S}(0)$ as an electron source and produce $\mathrm{SO}_{3}{ }^{2-}$ by sulfur dioxygenase (sdo). In brief, these findings indicated a coordination in sulfur cycling among sediment autotrophs.

\section{Autotrophic nitrogen-cycling capabilities along a salinity gradient}

To better assess the role of sediment autotrophic microbes in nutrient cycling, we reconstructed key nitrogen utilization pathways (Additional file 8: Table S7). This revealed that $~ 15 \%$ of the MAGs, most prevalent in the moderate salinity $G 3$ sites ( $t$ test, all $P<0.05$ ), possessed nitrogenase (nifDKH) genes, suggesting they are autotrophic diazotrophic bacteria, an important nutrient source in the lake. In previous studies, the fixation of inorganic carbon and nitrogen by such microorganisms was recognized as a crucial process to the development of life in extreme environments [72, 73]. In the G3 sediments, autotrophic microbial communities were dominated by diazotrophs, which was also found in some Tibetan soils [74], and the reason for this phenomenon is still mysterious. Dissimilatory nitrate reduction pathway was detected in a few MAGs affiliated with the Betaproteobacteria $(n=7)$, Deltaproteobacteria $(n=2)$ and Gammaproteobacteria $(n=1)$, with the highest species number and fraction in the freshwater G1 sites (Fig. 4). More than a half of the individuals $(n=59)$ identified here involved in denitrification, but only Rhodocyclaceae S06.Bin133 is capable of complete denitrification (to $\mathrm{N}_{2}$ ) and considered as an autotrophic sulfide-oxidizing denitrifier, and four species affiliated with the Alphaproteobacteria (Rhodobacteraceae S24.Bin137) and Gammaproteobacteria (S13.Bin138, S22.Bin169 and Thiotrichaceae S06.Bin195) code a partial pathway for nitrite to nitrogen. This suggests a coordination in denitrification among sediment autotrophs. Autotrophic nitrate-reducing and denitrifying bacteria are commonly found in sediments $[75,76]$, and the coupling of carbon fixation, nitrate reduction and oxidation of reduced sulfur compounds performed by such microorganisms is successfully applied to wastewater treatment $[77,78]$. Urease genes (ureDABCEFG) genes were identified in 14 MAGs (Fig. 2), suggesting these species could acquire $\mathrm{C}$ and $\mathrm{N}$ by hydrolyzing urea to ammonia and carbon dioxide [79], which then could be fixed to yield glucose via a carbon fixation pathway. The number of species and the fraction of these potential urea-utilizers declined with increased salinity (both $P<0.001$, Fig. 4). Two abundant species Hydrogenophaga S05.Bin024 and S04.Bin021 in the freshwater G1 sites possess the capability of urea utilization, evidenced by previous research [80]. To our surprise, genes encoding ammonia monooxygenase, which is responsible for the transformation from ammonia to hydroxylamine [81], were not detected in any of the MAGs. However, 42 MAGs likely participated in a partial process of 
nitrification (converting hydroxylamine to nitrate). In general, autotrophic microorganisms in Xiaochaidan Lake sediments likely use multiple strategies to gain nitrogen resources for growth, illustrating that they are important participants in the nitrogen cycle.

\section{Iron metabolism by the sediment autotrophs}

Iron is a ubiquitously abundant redox active transition metal in sedimentary systems [82], serving as an essential nutrient and an electron donor or acceptor to many prokaryotes [83]. More than a half $(\sim 56 \%)$ of the MAGs encode proteins with similarity to iron oxidase (iro) or/and sulfocyanin and the $\mathrm{cbb}_{3}$-type oxidase (ccoNOQP) (Additional file 9: Table S8), suggesting they are capable of transferring electrons to oxidases during iron oxidation [84]. This suggests that many autotrophic microbes in Xiaochaidan Lake sediments are also oxidizing iron, consistent with that abundant bacteria could oxidize iron in lake sediments [85]. Among them, eight were inferred to catalyze nitrate-dependent Fe(II) oxidation under anaerobic conditions, which have been observed in several different sediments [86, 87], suggesting a tight coupling of $\mathrm{Fe}$ and $\mathrm{N}$ redox cycles in anaerobic sedimentary environments that has significant implications for mechanisms of $\mathrm{NO}_{3}{ }^{-}$removal and the regeneration of reactive $\mathrm{Fe}$ (III) oxides in hydromorphic sediments, as well as the transformation of various natural and contaminant organic and inorganic compounds [83]. It was notable that the species number and fraction of the MAGs with the sulfocyanin-encoding gene were significantly negatively associated with salinity (both $P<0.001$ ). In the freshwater $\mathrm{G} 1$ sites, the most dominant species Rhodoferax S03.Bin061 codes for sulfocyanin to oxidize iron, inconsistent with the fact that the Rhodoferax species are Fe(III)-reducers [88, 89]. In addition to iron oxidation, 10 MAGs possessed ferric-chelate reductase (feR-like) gene, potentially catalyzing ferric iron reduction with $\mathrm{NAD}(\mathrm{P}) \mathrm{H}$ as the electron donor [90]. FeR was first characterized in a strictly anaerobic sulfate-reducing archaeon, Archaeoglobus fulgidus [91]. Intriguingly, among the above-mentioned 10 ferR-like gene-containing MAGs, four deltaproteobacterial species (Desulfotignum S09.Bin188 and S14.Bin031, and Desulfobacteraceae S24.Bin046 and S24.Bin080) also had the potential to perform sulfate reduction. In addition, the $\mathrm{mtrB} / \mathrm{pioB}$-like genes encoding decaheme-associated outer membrane proteins of MtrB/PioB family were identified in 19 MAGs, which are common among $\mathrm{Fe}(\mathrm{II})$ oxidizers and Fe(III) reducers [92]. These findings implied that autotrophic microorganisms likely be important players in the biogeochemical cycle of iron (especially iron oxidation) in sedimentary systems.

\section{Increased physiological efficiency of sediment autotrophs in response to increased salinity}

This study revealed that autotrophic prokaryotes in lacustrine sediments were taxonomically diverse with metabolic versatility, suggesting that autotrophs have wider biogeochemical niches. The comparison of the freshwater $\mathrm{G} 1$ and hypersaline $\mathrm{G} 5$ sediments illustrated that carbon-fixing microorganisms with higher physiological efficiency were selected by high salinity. The conclusion was supported by the following three reasons: 1) Different electron donors could affect the carbon fixation efficiency [93] and the changes in electron donors and acceptors resulted in the decline of energy generated with increasing salinity, because the main reactions changed from highly exergonic (such as the oxidation of sulfide and 
ferrous iron and dissimilatory nitrate reduction) to low exergonic (such as $\mathrm{CO}$ oxidation and dissimilatory sulfate reduction) [94]; 2) The dominant pathway of glycolysis shifted from ED to more exergonic EMP [53] with increasing salinity; 3) The dominant CBB carbon fixation pathway was replaced by more energy efficient WL pathway [44] from freshwater to hypersaline sediments.

\section{Conclusions}

Here we leveraged genome-resolved metagenomic analysis to characterize how the composition and metabolic capabilities of carbon-fixing microbes shift along a salinity gradient in lacustrine sediments. In the sediment autotrophic community composed of these retrieved 117 MAGs, a shift in the predominant lineage from Betaproteobacteria to Deltaproteobacteria was observed with increasing salinity, and the variation in this community composition was mainly driven by salinity, $\mathrm{pH}$ and TOC. This is the first systematic attempt to characterize how carbon fixation pathways respond to salinity, and the results indicate that the predominant pathways change from the CBB cycle to more energy efficient WL pathway from freshwater to hypersaline sediments. Physiological inference of these genomes implies that sediment autotrophs are linked to the oxidation of reduced sulfur compounds, ferrous iron and carbon monoxide, dissimilatory sulfate and nitrate reduction, denitrification and nitrogen fixation, suggesting the importance of autotrophic microorganisms in the biogeochemical cycle, and shows a selection of autotrophs with higher physiological efficiency by high salinity. Approximately $21 \%$ of these MAGs belonging to unknown orders suggest that autotrophs are more taxonomical and functional diversity and their biogeochemical niches are wider. These results contribute to our understanding of the response of autotrophic microbial community to salinity change and provide potential strategies for genome-enable cultivation of novel autotrophic microorganisms from saline environments. Further study is needed to characterize ecological functions of carbon-fixing prokaryotes by using "omics" and stable isotope probing (SIP) technologies, to better understand their occupied niches, response to environmental disturbance and contribution to the biogeochemical cycling of life-essential elements.

\section{Methods}

\section{Site description, sampling, geochemical measurements, and DNA extraction and sequencing}

Xiaochaidan Lake $\left(37^{\circ} 27^{\prime}-37^{\circ} 31^{\prime} \mathrm{N}, 95^{\circ} 25^{\prime}-95^{\circ} 35^{\prime} \mathrm{E}\right)$ is a salty lake near the northeastern edge of Qaidam Basin (Fig. 1a). In the past forty years, the surface area has experienced expansion, reduction, and expansion again to its current size of $103.94 \mathrm{~km}^{2}$ [95]. This lake has no outlet but is fed by a freshwater river, Tataling River, at its northwestern margin, and groundwater. In November 2016, 25 surface sediment samples were collected at $\sim 1.0 \mathrm{~m}$ water depth, along the shoreline, from Tataling River in northwestern corner to southeastern margin of the lake. A sterile spade, washed with ethanol and in situ lake water before use, was used to collect sediments into $50 \mathrm{ml}$ sterile centrifuge tubes. The samples for DNA 
extraction were immediately frozen in dry ice until return to the laboratory, and then stored at $-80{ }^{\circ} \mathrm{C}$ for further analysis.

Sediment pore water was collected by centrifugation $\left(5,000 \times \mathrm{g}, 10 \mathrm{~min}, 4^{\circ} \mathrm{C}\right)$, and was used to measure $\mathrm{pH}$ and salinity with a meter PP-20 (Sartorius, Germany). The concentrations of major ions (e.g., $\mathrm{Na}^{+}, \mathrm{K}^{+}$, $\mathrm{Ca}^{2+}, \mathrm{Mg}^{2+}, \mathrm{Cl}^{-}$and $\mathrm{SO}_{4}{ }^{2-}$ ) were determined by using a Dionex DX 600 ion chromatography (Dionex, USA). Additionally, total organic carbon (TOC) and dissolved organic carbon (DOC) were measured with a Multi N/C 2100S analyzer (Analytik Jena, Germany). Physicochemical characteristics were summarized in Additional file 10: Table S9.

For the 25 sediment samples, genomic DNA was extracted with our modified phenol/chloroform method [96]. The quality and quantity of extracted DNA were checked by using agarose gel electrophoresis and a Nano-Drop 2000 spectrophotometer, respectively. Standard shotgun libraries of 300-bp in insert size were prepared at the Guangdong Magigene Company, and were sequenced on an Illumina HiSeq 4000 platform (paired-end 150-bp mode).

\section{Genome-resolved metagenomic analysis}

All raw reads were dereplicated using an in-house perl script, and the resulting unique reads were trimmed based on quality scores using Sickle (version 1.33) with the parameters "-q 20 -I 50" [97]. The 25 individual samples were each assembled de novo to obtain 25 separate assemblies using SPAdes (version 3.11.0) with the parameters "-k 21, 33, 55, 77 -meta" [98]. For each sample, the scaffold coverage was calculated by mapping the qualified reads to the assembled scaffolds (length $\geq 2000 \mathrm{bp}$ ) with BBMap. These scaffolds were clustered into genome bins based on their tetranucleotide frequencies and coverages using MetaBAT 2 with the parameters "-m 2000 --unbinned" [99].

These retrieved genomes were further used to call genes with the single mode of Prodigal [100], and these predicted genes were annotated against the Pfam, KEGG, eggNOG, and NCBI-nr databases. According to the above results, genomes containing all key genes of any carbon fixation pathway were aggregated, dereplicated, and optimized using dRep [101] and ESOM [102]. For obtaining high-quality genomes, the best representative from each cluster was further optimized and re-assembled as previously described [68].

Next, the optimized genome bins were evaluated for taxonomic assignment, genome completeness, potential contamination, and strain heterogeneity using CheckM [103]. The predicted gene functions were manually curated and modified by comparing to the NCBI-nr, KEGG, eggNOG, Pfam, and in-house databases. Subsequently, metabolic pathways of each bin were constructed based on gene annotation. The 16S rRNA gene sequences identified by CheckM were used to help ensure taxonomy by searching for the closely related sequences in NCBI GenBank with BLASTn, whilst taxonomic assignment of these genomes was confirmed by phylogenomic analyses. Lastly, calculation of relative abundances of these genomes in communities was described in the Supplementary Information.

\section{Phylogenetic analyses}

Page 14/30 
The 117 genomes retrieved in this study and 544 reference genomes available in the NCBI prokaryote genome database and the Integrated Microbial Genomes and Microbiomes (IMG/M) online database were used to construct a phylogenomic tree based on a concatenated alignment of 32 marker genes (Additional file 11: Table S10) as previously suggested [104]. Specifically, marker proteins were identified in these genomes with hmmsearch (version 3.1b1) using specific hidden Markov models. Each of the 32 marker protein sequences was aligned using MAFFT (version 7.313) with the parameters "-localpair maxiterate 1000" [105], and subsequently filtered with trimAl 1.4 to remove columns comprised of $\geq 95 \%$ gaps [106]. Then the curated alignments were concatenated, and a phylogenetic tree was built using IQTREE (version 1.6.10) with the parameters "LG + I+G4 -alrt 1000 -bb 1000" [107]. For the phylogenetic analysis of functional marker proteins ( $R b c L$ and $D s r A B)$, the respective protein sequences were collected from the previous studies $[12,67,108]$. Alignment and filtering were performed with the same programs as described above. Phylogenetic trees were constructed using IQ-TREE with the parameters "-m TEST alrt 1000 -bb 1000". The newick files with the best tree topology were uploaded to iTOL for visualization and formatting [109].

\title{
Statistical analyses
}

The fraction of potential carbon fixers with a given function in the potential carbon-fixing community was determined by:

\author{
$\sum$ total relative abundance of potential carbon fixers with function $X$ \\ $\sum$ total relative abundace of potential carbon fixing community
}

All statistical analyses were implemented using SPSS 18.0, Origin 9.0, SigmaPlot 10.0 and various $R$ packages (http://www.rproject.org). The relationship between the potential carbon-fixing community and environmental variables was analyzed using canonical correspondence analysis (CCA), while variance partitioning analysis was applied to determine the independent contributions of these environmental factors to the variation in community composition. The significances of differences in the number of species and the fractions of potential carbon fixers with specific functions among five groups were tested by one-way ANOVA and t test analyses.

\section{Abbreviations}

MAGs: Metagenome-assembled genomes; CBB: Calvin-Benson-Bassham cycle; rTCA: reductive citric acid cycle; WL: Wood-Ljungdahl pathway; 3-HP: 3-hydroxypropionate bicycle; rGly: reductive glycine pathway; TOC: Total organic carbon; DOC: Dissolved organic carbon; CCA: Canonical correspondence analysis; PPP: Pentose phosphate pathway; EMP: Embden-Meyerhof-Parnas pathway; ED: Entner-Doudoroff pathway; AAP: Aerobic anoxygenic photosynthetic

\section{Declarations}


Not applicable.

\section{Funding}

This work was financially supported by the National Natural Science Foundation of China (Grant Nos. 91751206, 31600077, 41603074, 41521001, 41630103, 41622106, 41773132, 41972317 and 91647115), the 111 Program (State Administration of Foreign Experts Affairs \& the Ministry of Education of China, grant no. B18049), Fundamental Research Funds for the Central Universities, China University of Geosciences (Wuhan) and State Key Laboratory of Biogeology and Environmental Geology, CUG (No. GBL11805).

\section{Availability of data and materials}

All data generated during this study is available at the Sequence Read Archive (SRA) under BioProject number PRJNA594844.

\section{Author's contributions}

JL, YF, HCJ, BPH, BGZ, LNH, WJL, JTL, WSS, HLD and BJB conceived the study. JY and GW collected the samples. JL, YF, ZSH, YZS and JLL performed metagenomic analysis, genome binning, functional annotation and statistical analyses. JL, YF, HCJ, BPH, HLD and BJB draft the manuscript. All authors read and approved the final manuscript.

\section{Ethics approval and consent to participate}

Not applicable

\section{Consent for publications}

Not applicable

\section{Competing interests}

The authors declare that they have no competing interests.

\section{References}

1. Ducat DC, Silver PA. Improving carbon fixation pathways. Curr Opin Chem Biol. 2012;16:337-344.

2. Field CB, Behrenfeld MJ, Randerson JT, Falkowski P. Primary production of the biosphere: integrating terrestrial and oceanic components. Science. 1998;281:237-240.

3. Basu S, Mackey KRM. Phytoplankton as Key Mediators of the Biological Carbon Pump: Their Responses to a Changing Climate. Sustainability. 2018;10:869.

4. Yue L, Kong W, Ji M, Liu J, Morgan-Kiss RM. Community response of microbial primary producers to salinity is primarily driven by nutrients in lakes. Sci Total Environ. 2019;696:134001. 
5. Berg IA. Ecological aspects of the distribution of different autotrophic $\mathrm{CO}_{2}$ fixation pathways. Appl Environ Microbiol. 2011;77:1925-1936.

6. Figueroa IA, Barnum TP, Somasekhar PY, Carlström Cl, Engelbrektson AL, Coates JD. Metagenomicsguided analysis of microbial chemolithoautotrophic phosphite oxidation yields evidence of a seventh natural $\mathrm{CO}_{2}$ fixation pathway. Proc Natl Acad Sci USA. 2018;115:E92-E101.

7. Cotton $\mathrm{CA}$, Edlich-Muth $\mathrm{C}$, Bar-Even A. Reinforcing carbon fixation: $\mathrm{CO}_{2}$ reduction replacing and supporting carboxylation. Curr Opin Biotechnol. 2018;49:49-56.

8. Mall A, Sobotta J, Huber C, Tschirner C, Kowarschik S, Bačnik K et al. Reversibility of citrate synthase allows autotrophic growth of a thermophilic bacterium. Science. 2018;359:563-567.

9. Nunoura T, Chikaraishi Y, Izaki R, Suwa T, Sato T, Harada T et al. A primordial and reversible TCA cycle in a facultatively chemolithoautotrophic thermophile. Science. 2018;359:559-563.

10. Hügler M, Gärtner A, Imhoff JF. Functional genes as markers for sulfur cycling and $\mathrm{CO}_{2}$ fixation in microbial communities of hydrothermal vents of the Logatchev field. FEMS Microbiol Ecol. 2010;73:526-537.

11. Tabita FR, Satagopan S, Hanson TE, Kreel NE, Scott SS. Distinct form I, II, III, and IV Rubisco proteins from the three kingdoms of life provide clues about Rubisco evolution and structure/function relationships. J Exp Bot. 2008;59:1515-1524.

12. Jaffe AL, Castelle CJ, Dupont CL, Banfield JF, evolution. Lateral gene transfer shapes the distribution of RuBisCO among Candidate Phyla Radiation bacteria and DPANN archaea. Mol Biol Evol. 2018;36:435-446.

13. Könneke M, Bernhard AE, José R, Walker $C B$, Waterbury JB, Stahl DA. Isolation of an autotrophic ammonia-oxidizing marine archaeon. Nature. 2005;437:543.

14. Tully BJ, Graham ED, Heidelberg JF. The reconstruction of 2,631 draft metagenome-assembled genomes from the global oceans. Sci Data. 2018;5:170203.

15. Wrighton KC, Thomas BC, Sharon I, Miller CS, Castelle CJ, VerBerkmoes NC et al. Fermentation, hydrogen, and sulfur metabolism in multiple uncultivated bacterial phyla. 2012;337:1661-1665.

16. Emerson JB, Thomas BC, Alvarez W, Banfield JFJEm. Metagenomic analysis of a high carbon dioxide subsurface microbial community populated by chemolithoautotrophs and bacteria and archaea from candidate phyla. Environ Microbiol. 2016;18:1686-1703.

17. Wetzel RG. Limnology: lake and river ecosystems. Gulf Professional Publishing; 2001.

18. Zorz JK, Sharp C, Kleiner M, Gordon PM, Pon RT, Dong X et al. A shared core microbiome in soda lakes separated by large distances. Nat Commun. 2019;10:4230.

19. Vavourakis CD, Andrei A-S, Mehrshad M, Ghai R, Sorokin DY, Muyzer G. A metagenomics roadmap to the uncultured genome diversity in hypersaline soda lake sediments. Microbiome. 2018;6:168.

20. Tranvik LJ, Downing JA, Cotner JB, Loiselle SA, Striegl RG, Ballatore TJ et al. Lakes and reservoirs as regulators of carbon cycling and climate. Limnol Oceanogr. 2009;54:2298-2314. 
21. Raymond PA, Hartmann J, Lauerwald R, Sobek S, McDonald C, Hoover M et al. Global carbon dioxide emissions from inland waters. Nature. 2013;503:355.

22. Lozupone CA, Knight R. Global patterns in bacterial diversity. Proc Natl Acad Sci USA. 2007;104:11436-11440.

23. Jiang H, Dong H, Yu B, Liu X, Li Y, Ji S et al. Microbial response to salinity change in Lake Chaka, a hypersaline lake on Tibetan plateau. Environ Microbiol. 2007;9:2603-2621.

24. Herlemann DP, Labrenz M, Jürgens K, Bertilsson S, Waniek JJ, Andersson AF. Transitions in bacterial communities along the $2000 \mathrm{~km}$ salinity gradient of the Baltic Sea. ISME J. 2011;5:1571.

25. Oren A. Thermodynamic limits to microbial life at high salt concentrations. Environ Microbiol. 2011;13:1908-1923.

26. Yang J, Ma La, Jiang H, Wu G, Dong H. Salinity shapes microbial diversity and community structure in surface sediments of the Qinghai-Tibetan Lakes. Sci Rep. 2016;6:25078.

27. Liu W, Jiang H, Yang J, Wu G. Gammaproteobacterial diversity and carbon utilization in response to salinity in the lakes on the Qinghai-Tibetan Plateau. Geomicrobiol J. 2018;35:392-403.

28. Jain C, Rodriguez-R LM, Phillippy AM, Konstantinidis KT, Aluru S. High throughput ANI analysis of 90K prokaryotic genomes reveals clear species boundaries. Nat Commun. 2018;9:5114.

29. Bowers RM, Kyrpides NC, Stepanauskas R, Harmon-Smith M, Doud D, Reddy T et al. Minimum information about a single amplified genome (MISAG) and a metagenome-assembled genome (MIMAG) of bacteria and archaea. Nat Biotechnol. 2017;35:725.

30. Xiong J, Liu Y, Lin X, Zhang H, Zeng J, Hou J et al. Geographic distance and pH drive bacterial distribution in alkaline lake sediments across Tibetan Plateau. Environ Microbiol. 2012;14:24572466.

31. Hollister EB, Engledow AS, Hammett AJM, Provin TL, Wilkinson HH, Gentry TJ. Shifts in microbial community structure along an ecological gradient of hypersaline soils and sediments. 2010;4:829.

32. Li D, Sharp JO, Saikaly PE, Ali S, Alidina M, Alarawi MS et al. Dissolved organic carbon influences microbial community composition and diversity in managed aquifer recharge systems. Appl Environ Microbiol. 2012;78:6819-6828.

33. Sudhir P, Murthy S. Effects of salt stress on basic processes of photosynthesis. Photosynthetica. 2004;42:481-486.

34. Ashraf M, Harris PJ. Photosynthesis under stressful environments: an overview. Photosynthetica. 2013;51:163-190.

35. Abed RM, Kohls K, De Beer D. Effect of salinity changes on the bacterial diversity, photosynthesis and oxygen consumption of cyanobacterial mats from an intertidal flat of the Arabian Gulf. Environ Microbiol. 2007;9:1384-1392.

36. Logares R, Bråte J, Bertilsson S, Clasen JL, Shalchian-Tabrizi K, Rengefors KJ. Infrequent marinefreshwater transitions in the microbial world. Trends Microbiol. 2009;17:414-422. 
37. Logares R, Lindström ES, Langenheder S, Logue JB, Paterson H, Laybourn-Parry J et al. Biogeography of bacterial communities exposed to progressive long-term environmental change. ISME J. 2013;7:937.

38. Sato T, Atomi H, Imanaka T. Archaeal type III RuBisCOs function in a pathway for AMP metabolism. Science. 2007;315:1003-1006.

39. Risso C, Sun J, Zhuang K, Mahadevan R, DeBoy R, Ismail W et al. Genome-scale comparison and constraint-based metabolic reconstruction of the facultative anaerobic Fe (III)-reducer Rhodoferax ferrireducens. BMC Genomics. 2009;10:447.

40. Kaden R, Spröer C, Beyer D, Krolla-Sidenstein P. Rhodoferax saidenbachensis nov., a psychrotolerant, very slowly growing bacterium within the family Comamonadaceae, proposal of appropriate taxonomic position of Albidiferax ferrireducens strain T118T in the genus Rhodoferax and emended description of the genus Rhodoferax. Int J Syst Evol Microbiol. 2014;64:1186-1193.

41. Lee SN, Kim YM, Cells. Cloning and characterization of ribulose bisphosphate carboxylase gene of a carboxydobacterium, Hydrogenophaga pseudoflava DSM 1084. Molecules. 1998;8.

42. Gunde-Cimerman N, Plemenitaš A, Oren A. Strategies of adaptation of microorganisms of the three domains of life to high salt concentrations. FEMS Microbiol Rev. 2018;42:353-375.

43. Bremer E, Krämer R. Responses of microorganisms to osmotic stress. Annu Rev Microbiol. 2019;73.

44. Fuchs G. Alternative pathways of carbon dioxide fixation: insights into the early evolution of life? Annu Rev Microbiol. 2011;65:631-658.

45. Knauth LP. Salinity history of the Earth's early ocean. Nature. 1998;395:554.

46. Lane N, Allen JF, Martin W. How did LUCA make a living? Chemiosmosis in the origin of life. BioEssays. 2010;32:271-280.

47. Hügler M, Sievert SM. Beyond the Calvin cycle: autotrophic carbon fixation in the ocean. Ann Rev Mar Sci. 2011;3:261-289.

48. Kuever J, Könneke M, Galushko A, Drzyzga O. Reclassification of Desulfobacterium phenolicum as Desulfobacula phenolica nov. and description of strain SaxT as Desulfotignum balticum gen. nov., sp. nov. Int J Syst Evol Microbiol. 2001;51:171-177.

49. Schink B, Thiemann V, Laue H, Friedrich MW. Desulfotignum phosphitoxidans nov., a new marine sulfate reducer that oxidizes phosphite to phosphate. Arch Microbiol. 2002;177:381-391.

50. Ommedal H, Torsvik T. Desulfotignum toluenicum nov., a novel toluene-degrading, sulphate-reducing bacterium isolated from an oil-reservoir model column. Int J Syst Evol Microbiol. 2007;57:2865-2869.

51. Mattes TE, Alexander AK, Richardson PM, Munk AC, Han CS, Stothard P et al. The genome of Polaromonas strain JS666: insights into the evolution of a hydrocarbon-and xenobiotic-degrading bacterium, and features of relevance to biotechnology. Appl Environ Microbiol. 2008;74:6405-6416.

52. Jewell TN, Karaoz U, Bill M, Chakraborty R, Brodie EL, Williams KH et al. Metatranscriptomic analysis reveals unexpectedly diverse microbial metabolism in a biogeochemical hot spot in an alluvial aquifer. Front Microbiol. 2017;8:40. 
53. Bar-Even A, Flamholz A, Noor E, Milo R. Rethinking glycolysis: on the biochemical logic of metabolic pathways. Nat Chem Biol. 2012;8:509.

54. Jiang $\mathrm{H}$, Huang J, Yang J. Halotolerant and halophilic microbes and their environmental implications in saline and hypersaline lakes in Qinghai Province, China. In: Egamberdieva D, Birkeland NK, Panosyan H, Li WJ, editors. Extremophiles in Eurasian Ecosystems: Ecology, Diversity, and Applications. Singapore: Springer Nature Singapore Pte Ltd; 2018. p. 299-316.

55. Stincone A, Prigione A, Cramer T, Wamelink MM, Campbell K, Cheung E et al. The return of metabolism: biochemistry and physiology of the pentose phosphate pathway. Biol Rev. 2015;90:927963.

56. Moran MA, Miller WL. Resourceful heterotrophs make the most of light in the coastal ocean. Nat Rev Microbiol. 2007;5:792.

57. Xie H, Zafiriou OC. Evidence for significant photochemical production of carbon monoxide by particles in coastal and oligotrophic marine waters. Geophys Res Lett. 2009;36:L23606.

58. Peura S, Sinclair L, Bertilsson S, Eiler A. Metagenomic insights into strategies of aerobic and anaerobic carbon and nitrogen transformation in boreal lakes. Sci Rep. 2015;5:12102.

59. Béjà $\mathrm{O}$, Suzuki MT, Heidelberg JF, Nelson WC, Preston CM, Hamada T et al. Unsuspected diversity among marine aerobic anoxygenic phototrophs. Nature. 2002;415:630.

60. McKinlay JB, Harwood CS. Carbon dioxide fixation as a central redox cofactor recycling mechanism in bacteria. Proc Natl Acad Sci USA. 2010;107:11669-11675.

61. Graham E, Heidelberg J, Tully B. Potential for primary productivity in a globally-distributed bacterial phototroph. ISME J. 2018;12:1861.

62. Bueno E, Mesa S, Bedmar EJ, Richardson DJ, Delgado MJ. Bacterial adaptation of respiration from oxic to microoxic and anoxic conditions: redox control. Antioxid Redox Signal. 2012;16:819-852.

63. Borisov VB, Gennis RB, Hemp J, Verkhovsky MI. The cytochrome bd respiratory oxygen reductases. Biochim Biophys Acta Bioenerg. 2011;1807:1398-1413.

64. Pitcher RS, Watmough NJ. The bacterial cytochrome $\mathrm{cbb}_{3}$ Biochim Biophys Acta Bioenerg. 2004;1655:388-399.

65. Xie W, Wang F, Guo L, Chen Z, Sievert SM, Meng J et al. Comparative metagenomics of microbial communities inhabiting deep-sea hydrothermal vent chimneys with contrasting chemistries. ISME J. 2011;5:414.

66. Anantharaman K, Hausmann B, Jungbluth SP, Kantor RS, Lavy A, Warren LA et al. Expanded diversity of microbial groups that shape the dissimilatory sulfur cycle. ISME J. 2018;12:1715.

67. Tan S, Liu J, Fang Y, Hedlund BP, Lian Z-H, Huang L-Y et al. Insights into ecological role of a new deltaproteobacterial order Candidatus Acidulodesulfobacterales by metagenomics and metatranscriptomics. ISME J. 2019;13:2044-2057.

68. Belila A, Abbas B, Fazaa I, Saidi N, Snoussi M, Hassen A et al. Sulfur bacteria in wastewater stabilization ponds periodically affected by the 'red-water'phenomenon. Appl Microbiol Biotechnol. 
2013;97:379-394.

69. Hensen D, Sperling D, Trüper HG, Brune DC, Dahl C. Thiosulphate oxidation in the phototrophic sulphur bacterium Allochromatium vinosum. Mol Microbiol. 2006;62:794-810.

70. Sorokin DY, Muntyan MS, Panteleeva AN, Muyzer G. Thioalkalivibrio sulfidiphilus nov., a haloalkaliphilic, sulfur-oxidizing gammaproteobacterium from alkaline habitats. Int J Syst Evol Microbiol. 2012;62:1884-1889.

71. Sorokin DY, Tourova TP, Lysenko AM, Mityushina LL, Kuenen JG. Thioalkalivibrio thiocyanoxidans nov. and Thioalkalivibrio paradoxus sp. nov., novel alkaliphilic, obligately autotrophic, sulfuroxidizing bacteria capable of growth on thiocyanate, from soda lakes. Int J Syst Evol Microbiol. 2002;52:657-664.

72. Valdés J, Pedroso I, Quatrini R, Dodson RJ, Tettelin H, Blake R et al. Acidithiobacillus ferrooxidans metabolism: from genome sequence to industrial applications. BMC Genomics. 2008;9:597.

73. Shi L, Dong H, Reguera G, Beyenal H, Lu A, Liu J et al. Extracellular electron transfer mechanisms between microorganisms and minerals. Nat Rev Microbiol. 2016;14:651.

74. Che R, Deng Y, Wang F, Wang W, Xu Z, Hao Y et al. Autotrophic and symbiotic diazotrophs dominate nitrogen-fixing communities in Tibetan grassland soils. Sci Total Environ. 2018;639:997-1006.

75. Shao M-F, Zhang T, Fang HH-PJAm, biotechnology. Sulfur-driven autotrophic denitrification: diversity, biochemistry, and engineering applications. Appl Microbiol. 2010;88:1027-1042.

76. Laufer K, Røy H, Jørgensen BB, Kappler A. Evidence for the existence of autotrophic nitrate-reducing Fe (II)-oxidizing bacteria in marine coastal sediment. Appl Environ Microbiol. 2016;82:6120-6131.

77. Vaiopoulou E, Melidis P, Aivasidis A. Sulfide removal in wastewater from petrochemical industries by autotrophic denitrification. Water Res. 2005;39:4101-4109.

78. Chung J, Amin K, Kim S, Yoon S, Kwon K, Bae W. Autotrophic denitrification of nitrate and nitrite using thiosulfate as an electron donor. Water Res. 2014;58:169-178.

79. Williams TJ, Allen MA, DeMaere MZ, Kyrpides NC, Tringe SG, Woyke T et al. Microbial ecology of an Antarctic hypersaline lake: genomic assessment of ecophysiology among dominant haloarchaea. ISME J. 2014;8:1645.

80. Hayashi NR, Ishida T, Yokota A, Kodama T, Igarashi Y. Hydrogenophilus thermoluteolus nov., sp. nov., a thermophilic, facultatively chemolithoautotrophic, hydrogen-oxidizing bacterium. Int J Syst Evol Microbiol. 1999;49:783-786.

81. Daims H, Lebedeva EV, Pjevac P, Han P, Herbold C, Albertsen M et al. Complete nitrification by Nitrospira Nature. 2015;528:504.

82. Canfield DE, Thamdrup B, Hansen JW. The anaerobic degradation of organic matter in Danish coastal sediments: iron reduction, manganese reduction, and sulfate reduction. Geochim Cosmochim Acta. 1993;57:3867-3883.

83. Weber KA, Achenbach LA, Coates JD. Microorganisms pumping iron: anaerobic microbial iron oxidation and reduction. Nat Rev Microbiol. 2006;4:752. 
84. Bonnefoy V, Holmes DS. Genomic insights into microbial iron oxidation and iron uptake strategies in extremely acidic environments. Environ Microbiol. 2012;14:1597-1611.

85. Straub KL, Buchholz-Cleven BE. Enumeration and detection of anaerobic ferrous iron-oxidizing, nitrate-reducing bacteria from diverse European sediments. Appl Environ Microbiol. 1998;64:48464856.

86. Finneran $\mathrm{KT}$, Housewright ME, Lovley DR. Multiple influences of nitrate on uranium solubility during bioremediation of uranium-contaminated subsurface sediments. Environ Microbiol. 2002;4:510-516.

87. Senn DB, Hemond HF. Nitrate controls on iron and arsenic in an urban lake. Science. 2002;296:23732376.

88. Finneran KT, Johnsen CV, Lovley DR. Rhodoferax ferrireducens nov., a psychrotolerant, facultatively anaerobic bacterium that oxidizes acetate with the reduction of Fe (III). Int J Syst Evol Microbiol 2003;53:669-673.

89. Zhuang K, Izallalen M, Mouser P, Richter H, Risso C, Mahadevan R et al. Genome-scale dynamic modeling of the competition between Rhodoferax and Geobacter in anoxic subsurface environments. ISME J. 2011;5:305.

90. Schröder I, Johnson E, De Vries S. Microbial ferric iron reductases. FEMS Microbiol Rev. 2003;27:427447.

91. Vadas A, Monbouquette HG, Johnson E, Schröder I. Identification and characterization of a novel ferric reductase from the hyperthermophilic archaeon Archaeoglobus fulgidus. J Biol Chem. 1999;274:36715-36721.

92. Ilbert M, Bonnefoy V. Insight into the evolution of the iron oxidation pathways. Biochim Biophys Acta Bioenerg. 2013;1827:161-175.

93. Wang $Y$, Wang L, Shan $Y, H u$ J, Tsang $Y$, Hu Y et al. Optimization of inorganic carbon sources to improve the carbon fixation efficiency of the non-photosynthetic microbial community with different electron donors. Environ Technol. 2015;36:1246-1255.

94. Osburn MR, LaRowe DE, Momper LM, Amend JP. Chemolithotrophy in the continental deep subsurface: Sanford Underground Research Facility (SURF), USA. Front Microbiol. 2014;5:610.

95. Du Y, Liu B, He W, Zhou J, Duan S. Analysis on the variation and cause of the lake area in Qaidam Basin from 1976 to 2017. J Glaciol Geocryol. 2018;40:1275-1284.

96. Fang Y, Xu M, Chen X, Sun G, Guo J, Wu W et al. Modified pretreatment method for total microbial DNA extraction from contaminated river sediment. Front Environ Sci Eng. 2015;9:444-452.

97. Joshi N, Fass J. Sickle: a sliding-window, adaptive, quality-based trimming tool for FastQ files. 2011.

98. Bankevich A, Nurk S, Antipov D, Gurevich AA, Dvorkin M, Kulikov AS et al. SPAdes: a new genome assembly algorithm and its applications to single-cell sequencing. J Comput Biol. 2012;19:455-477.

99. Kang D, Li F, Kirton ES, Thomas A, Egan RS, An H et al. MetaBAT 2: an adaptive binning algorithm for robust and efficient genome reconstruction from metagenome assemblies. Peer J. 2019;7:e27522. 
100. Hyatt D, Chen G-L, LoCascio PF, Land ML, Larimer FW, Hauser LJ. Prodigal: prokaryotic gene recognition and translation initiation site identification. BMC Bioinformatics. 2010;11:119.

101. Olm MR, Brown CT, Brooks B, Banfield JF. dRep: a tool for fast and accurate genomic comparisons that enables improved genome recovery from metagenomes through de-replication. ISME J. 2017;11:2864.

102. Ultsch A, Mörchen F. ESOM-Maps: tools for clustering, visualization, and classification with Emergent SOM, University of Marburg: Germany, 2005.

103. Parks DH, Imelfort M, Skennerton CT, Hugenholtz P, Tyson GW. CheckM: assessing the quality of microbial genomes recovered from isolates, single cells, and metagenomes. Genome Res. 2015;25:1043-1055.

104. Hug LA, Baker BJ, Anantharaman K, Brown CT, Probst AJ, Castelle $C J$ et al. A new view of the tree of life. Nat Microbiol. 2016;1:16048.

105. Katoh K, Standley DM. MAFFT multiple sequence alignment software version 7: improvements in performance and usability. Mol Biol Evol. 2013;30:772-780.

106. Capella-Gutiérrez S, Silla-Martínez JM, Gabaldón T. trimAl: a tool for automated alignment trimming in large-scale phylogenetic analyses. Bioinformatics. 2009;25:1972-1973.

107. Nguyen L-T, Schmidt HA, von Haeseler A, Minh BQ. IQ-TREE: a fast and effective stochastic algorithm for estimating maximum-likelihood phylogenies. Mol Biol Evol. 2014;32:268-274.

108. Müller AL, Kjeldsen KU, Rattei T, Pester M, Loy A. Phylogenetic and environmental diversity of DsrABtype dissimilatory (bi) sulfite reductases. ISME J. 2015;9:1152.

109. Letunic I, Bork P. Interactive Tree of Life (iTOL): an online tool for phylogenetic tree display and annotation. Bioinformatics. 2006;23:127-128.

\section{Additional Files}

Additional file 1: Figure S1 The phylogenomic tree of the concatenated alignment of 32 marker genes. Bootstrap values are based on 100 replicates, and percentages $\geq 75 \%$ are shown with black squares, with that between $50 \%$ and $75 \%$ using white circles. Figure S2 The average relative abundances of different taxa in five salinity. Figure S3 The shared MAGs among 25 samples belonging to five salinity groups. Each line between any two samples means one shared MAG. Figure S4 The phylogenetic tree of the RubisCO lager subunit RbcL. Bootstrap values are based on 100 replicates, and only bootstrap values higher than $50 \%$ are shown with circles. The circle size means the bootstrap value. Figure S5 The phylogenetic tree of the concatenated DsrAB proteins. Bootstrap values are based on 100 replicates, and only bootstrap values higher than $50 \%$ are shown with red (between $50 \%$ and $75 \%$ ) and black ( $\geq 75 \%$ ) circles.

Additional file 2: Table S1. The information of metagenomic datasets and assembly results.

Additional file 3: Table S2. The number of genes assigned to five known pathways of carbon fixation. 
Additional file 4: Table S3. Summary of genomic characteristics of putative autotrophic microbes recovered from metagenomes

Additional file 5: Table S4. Relative abundances of these putative autotrophic microbes across 25 sediments.

Additional file 6: Table S5. The number of genes related to carbon metabolism and respiration.

Additional file 7: Table S6. The number of genes assigned to sulfur metabolism pathway.

Additional file 8: Table S7. The number of genes assigned to nitrogen metabolism.

Additional file 9: Table S8. The number of genes assigned to iron metabolism.

Additional file 10: Table S9. Physicochemical characteristics of sediment samples.

Additional file 11: Table S10. List of 32 marker proteins.

\section{Figures}
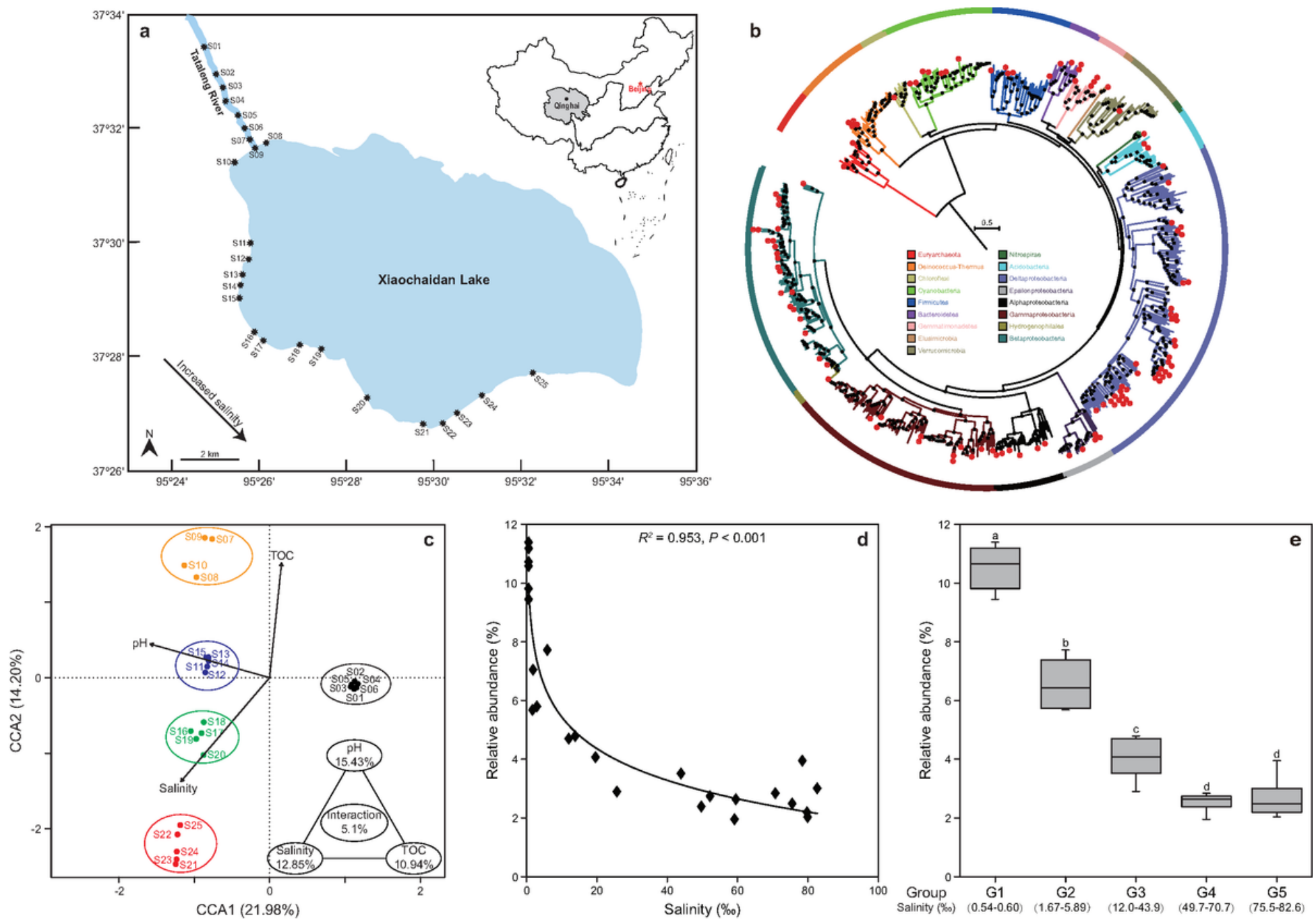


\section{Figure 1}

The retrieved MAGs with carbon fixation potential in lacustrine sediments. a Geographic location of 25 sediments collected from Xiaochaidan Lake and its inflow Tataling River. b Phylogenetic placement of the 117 retrieved MAGs. The phylogenomic tree was constructed using the concatenated alignment of 32 marker genes listed in Additional file 11: Table S10. A detailed tree is shown in Fig. S1. Bootstrap values are based on 100 replicates, and percentages $\geq 75 \%$ are shown with black squares. c Canonical correspondence analysis of the potential carbon-fixing community and environmental variables. $d$ The inverse relationship between the total relative abundance of all potential carbon-fixing microbes in each sample and the corresponding sediment salinity. e The average relative abundances of all potential carbon fixers in samples of each salinity groups showing a similar inverse relationship with salinity. Different letters above the bars indicate a significant difference between different groups at $5 \%$ level, according to one-way ANOVA with the Duncan test. Note: The designations employed and the presentation of the material on this map do not imply the expression of any opinion whatsoever on the part of Research Square concerning the legal status of any country, territory, city or area or of its authorities, or concerning the delimitation of its frontiers or boundaries. This map has been provided by the authors. 


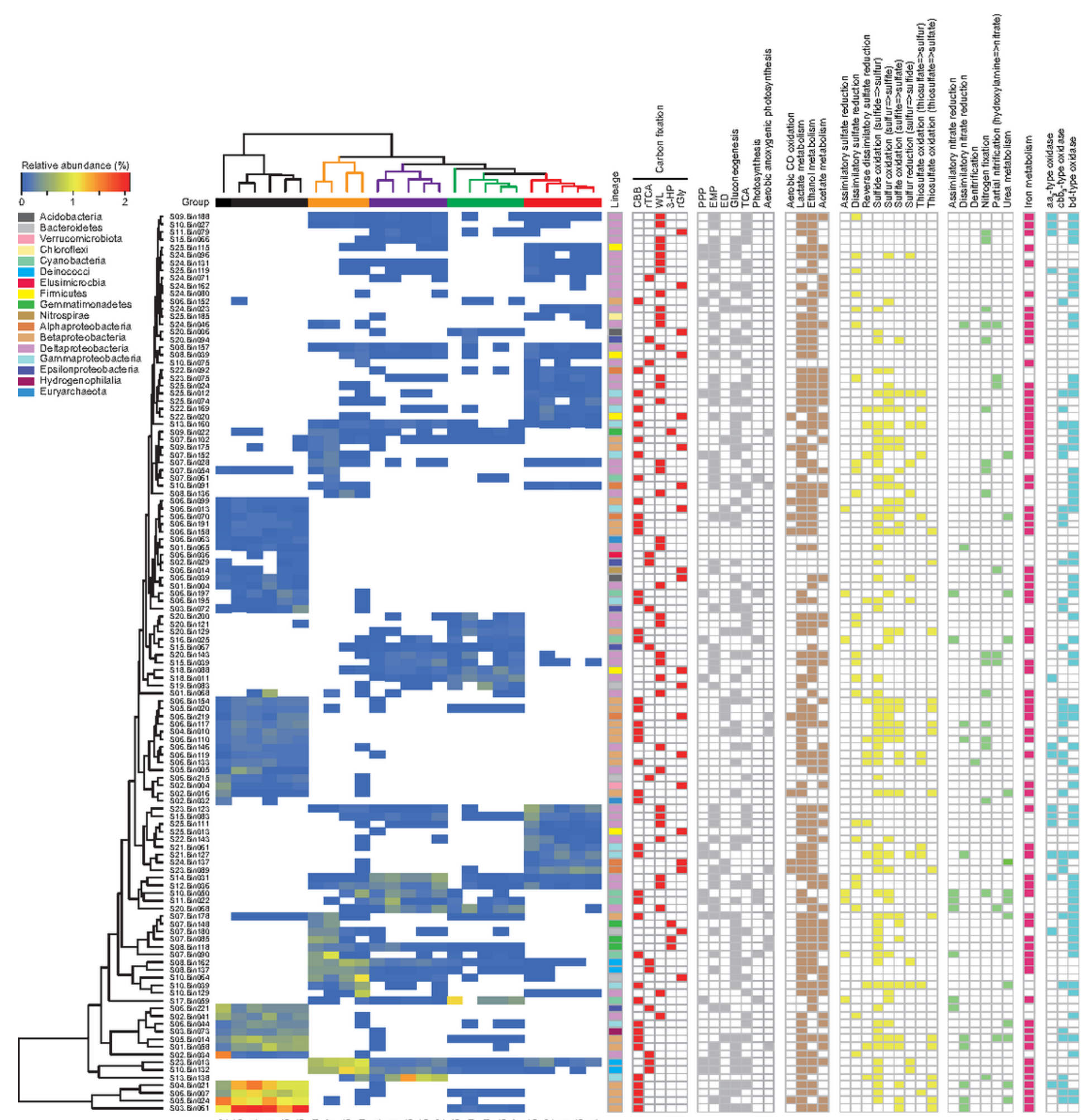

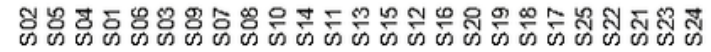

Figure 2

Heatmap plotting the abundance pattern of 117 MAGs, taxonomic lineages, and presence of metabolic pathways. MAGs were organized and clustered by the relative abundance and salinity. The data of relative abundances for each MAG is provided in Additional file 5: Table S4, and details of metabolic pathways are provided in Additional files: Tables S2 and S5-S8. CBB, Calvin-Benson-Bassham cycle; rTCA, reductive citric acid cycle; WL, Wood-Ljungdahl pathway; 3-HP, 3-hydroxypropionate bicycle; rGly, 
reductive glycine pathway; PPP, pentose phosphate pathway; EMP, Embden-Meyerhof-Parnas pathway; ED, Entner-Doudoroff pathway; TCA, citric acid cycle.
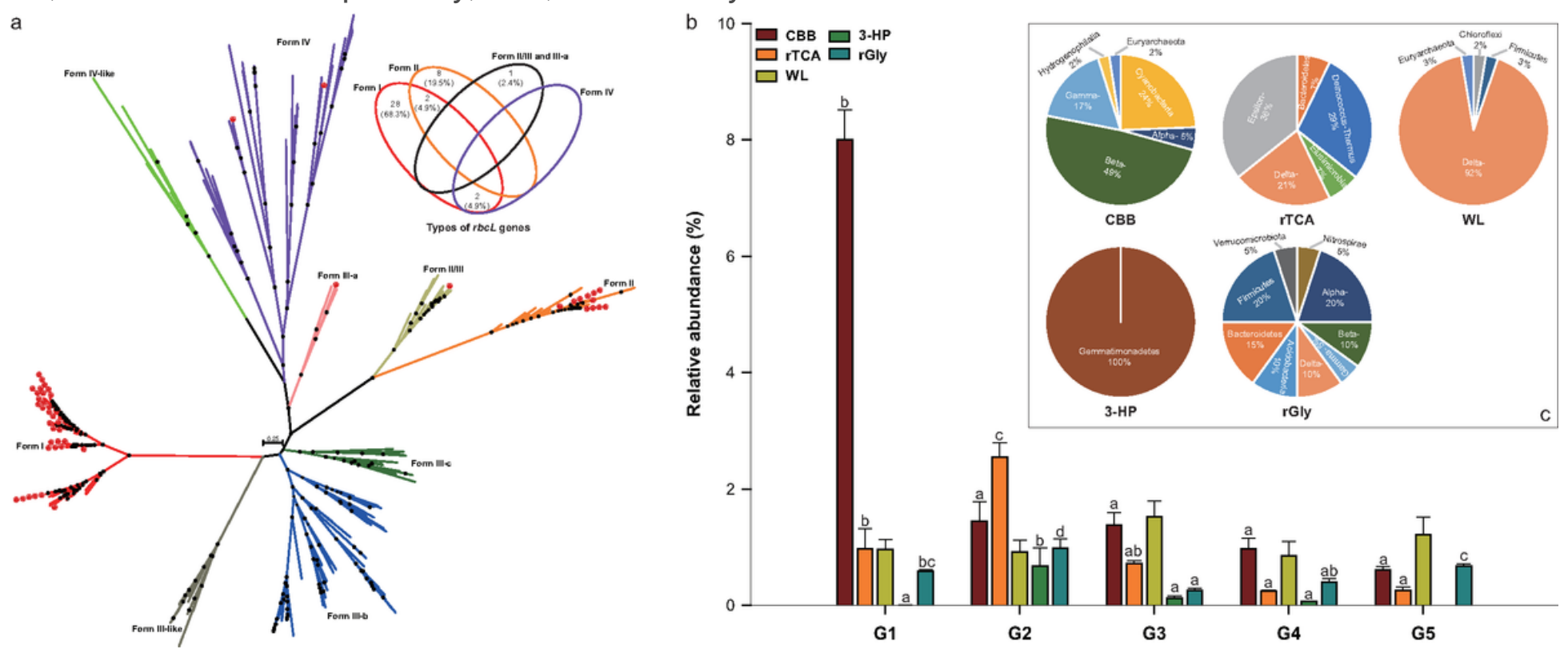

Figure 3

The pathways of carbon fixation identified in the 117 MAGs recovered from sediments. a The phylogenetic tree of the RubisCO lager subunit RbcL detected in these MAGs. The detail of this phylogenetic tree is provided in Additional file 1: Figure S4. Venn diagram depicts the number (percent) of the shared and unique forms of RubisCOs in these MAGs. b Relative abundances of these MAGs with different carbon fixation pathways across five salinity groups. Different letters above the bars within a specific pathway indicate significant differences between groups at the $5 \%$ level using one-way ANOVA with the Duncan test. In each pathway, the proportions of different lineages on the number of MAGs were showed in the pie diagram. 


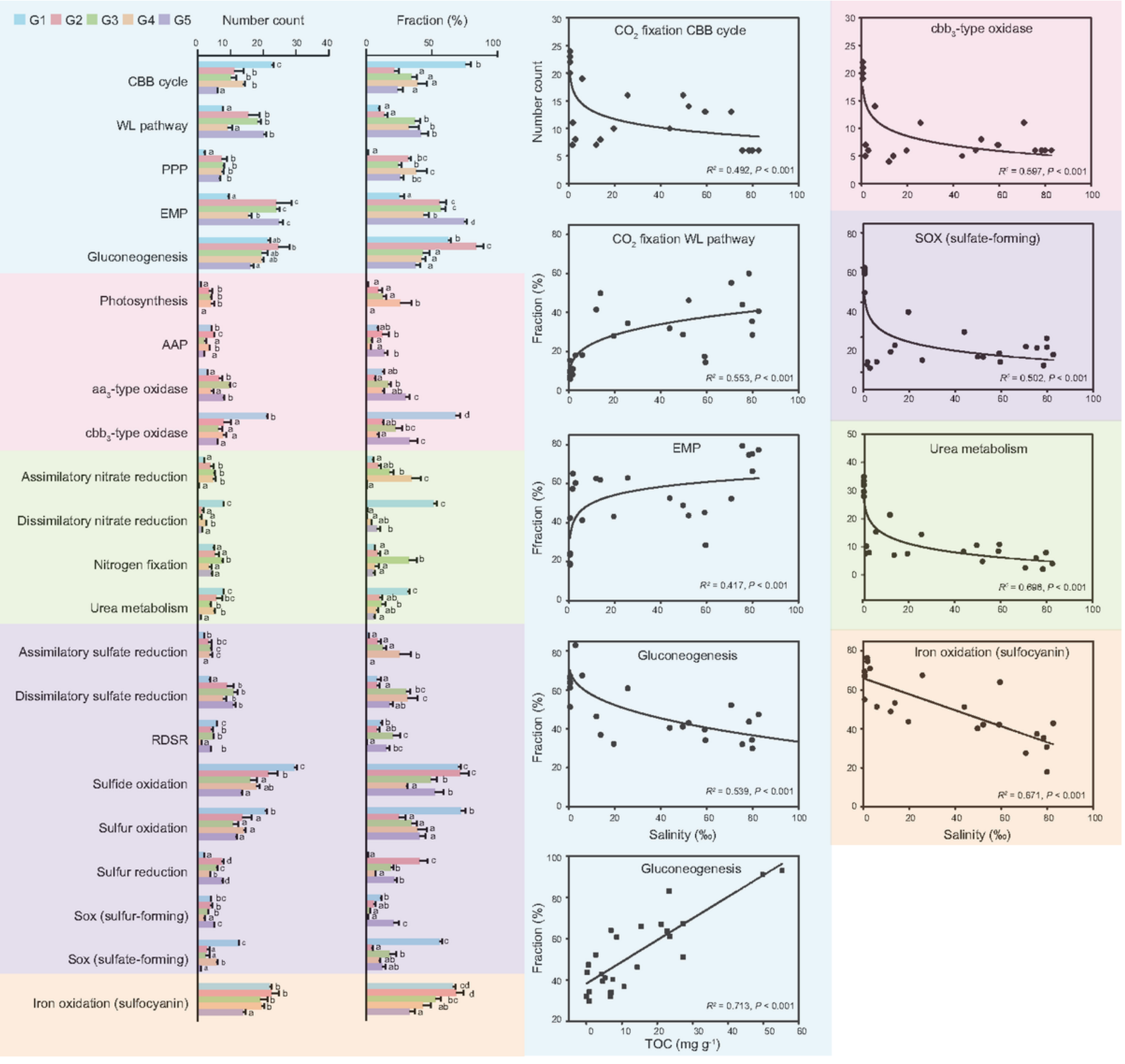

Figure 4

The species number and fraction of potential carbon-fixing MAGs with metabolic capabilities along the salinity gradient. 

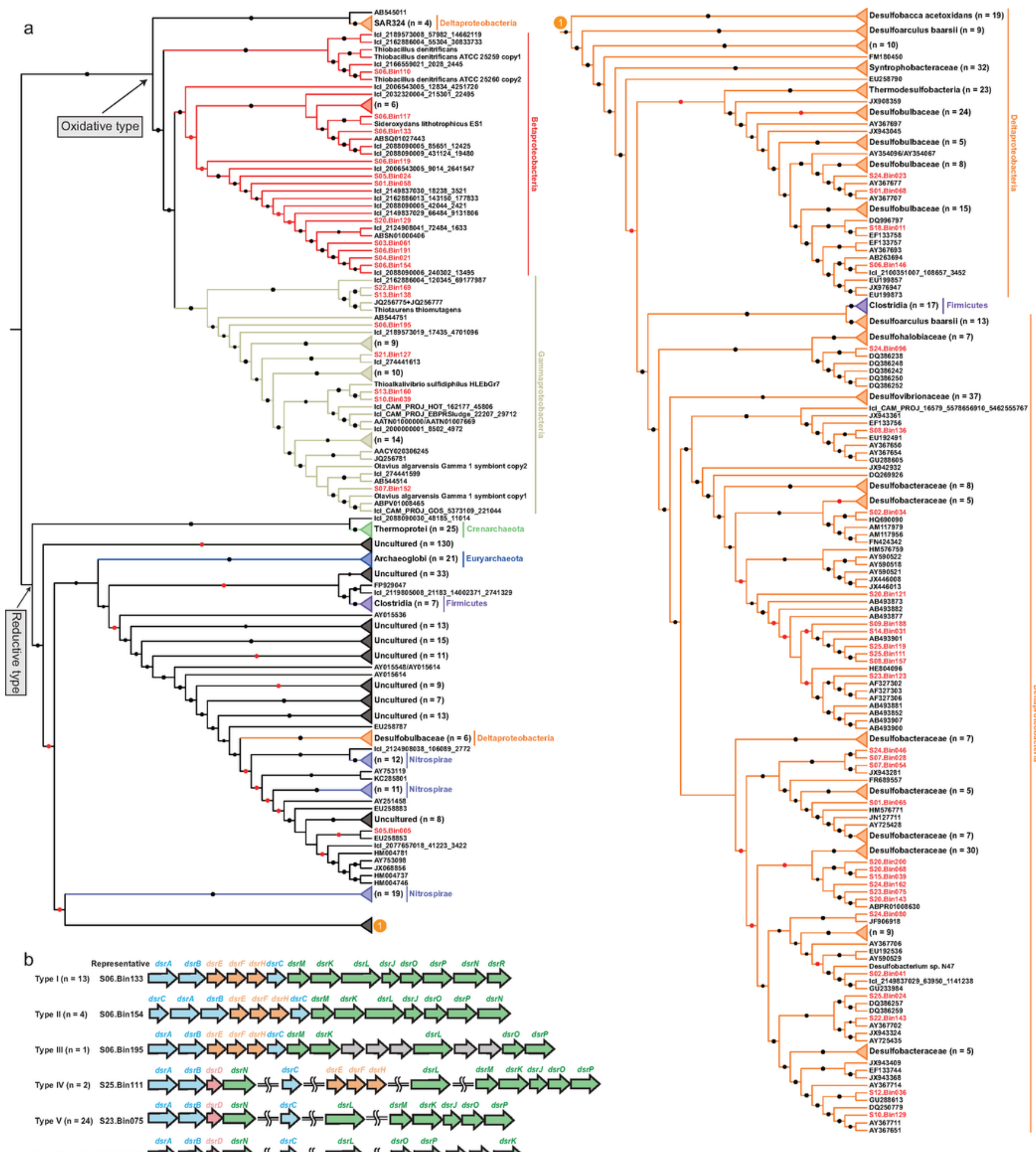

b

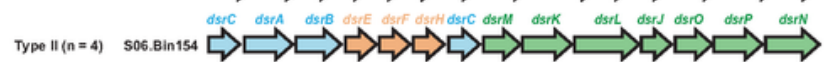

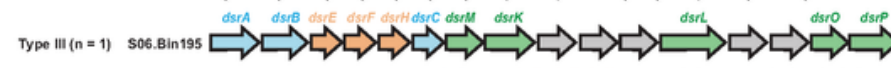

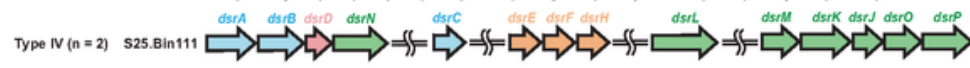

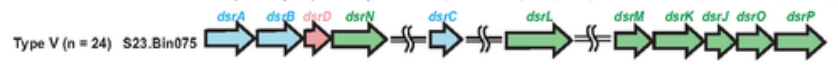

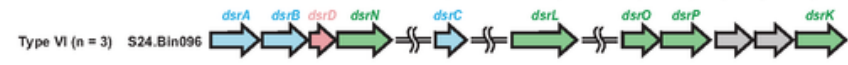

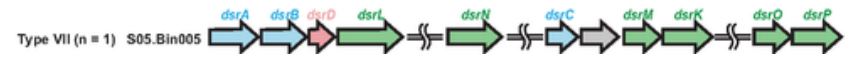

\section{Figure 5}

The dsr operons of MAGs with carbon fixation potential. a Phylogenic analysis of the concatenated DsrAB proteins. The detailed tree was provided in Additional file 1: Figure S5. Bootstrap values were based on 100 replicates, and only bootstrap values higher than $50 \%$ are shown with red (between $50 \%$ and $75 \%$ ) and black ( $\geq 75 \%$ ) circles. b The dsr operon structure in 48 putative autotrophic MAGs. The number of MAGs containing a specific dsr operon structure was showed within parentheses. 


\section{Supplementary Files}

This is a list of supplementary files associated with this preprint. Click to download.

- Tables2.xlsx

- TableS1.xIsx

- TableS7.xlsx

- TableS6.xlsx

- TableS8.xlsx

- TableS9.xlsx

- TableS10.xlsx

- TableS3.xlsx

- Supplementarylnformation.pdf

- TableS5.xIsx

- TableS4.xlsx 